\title{
Mathematical model of welding parameters for rapid prototyping using robot welding
}

\author{
F. Ribeiro, B. Ogunbiyi and J. Norrish
}

\begin{abstract}
Rapid Prototyping is a relatively new technology that allows the creation of prototypes in a very short period of time compared with traditional manufacturing techniques. First, a model of the prototype is drawn, using a computer aided design program, which is then mathematically 'sliced' and used to build the prototype layer by layer, using material such as paper, resins, or thermoplastics, depending on the process. The main disadvantage of these processes is that they do not allow metal as a raw material. Rapid Prototyping using Robot welding is another approach that overcomes this problem by using a welding robot that deposits metal. As the success of the final component quality depends very much on the welding parameters, it is important to automate their calculation. To automate the task of determining the welding parameters and to generate welded components with consistent quality, a very simple mathematical algorithm was created. The tests carried out to gather the necessary information to generate this model, the mathematical model itself, the limitations of the equations, and the tests to check their feasibility are described.

At the time the work was carried out, the authors were in the welding Engineering Groups, SIMS, Cranfield University, Cranfield, Beds. MK43 OSY, UK. Dr Ribeiro is now in the Department of Industrial Electronics, University of Minho, 4800 Guimarães, Portugal and Professor Norrish is in the Faculty of Engineering, University of Wollongong, Wollongong, NSW 2522, Australia. Manuscript received 12 May 1997; in final form 20 June 1997.

(C) 1997 The Institute of Materials
\end{abstract}

\section{INTRODUCTION}

Traditional Rapid Prototyping techniques cannot yet generate prototypes in $100 \%$ metal, although research is being carried out in this area. Another disadvantage is the high cost of the prototyping machines and the maximum volume they produce, which is relatively small. Rapid Prototyping using Robot Welding (RPURW) is a new approach to overcome some of the main disadvantages.

Research into this field has been carried out at Nottingham University by Phil Dickens et al. ${ }^{1,2}$ They used a similar approach to that described in the present work, but they did not integrate the computer aided design (CAD) with the entire system; only simple shapes were made and these were manually programmed. Even so, the shapes were not very promising as parts of some components collapsed. As a first attempt, this work was acceptable, although questions remain regarding whether the work was sufficiently automated and the quality of the final shapes. A quality analysis was made in the form of tensile testing, Vickers hardness testing, and microstructural analysis. The hardness results showed little variation along wall length but there was a marked increase in hardness moving from the bottom to the top of the wall in the final weld passes.

\section{RAPID PROTOTYPING USING ROBOT WELDING}

The RPURW process described by Ribeiro and Norrish $^{3,4}$ uses a Welding Robot that deposits weld beads, layer over layer, building up the prototype in this manner. The component shape is first drawn in a CAD program, then this solid is mathmatically 'sliced' into thin cross-sectional layers as described by Ribeiro and Norrish ${ }^{5}$. A robot program is then automatically generated according to the slices previously created, in such a way that the movement of the robot (while welding) will generate the part.

The setup comprises a welding robot, the welding power source, welding gas, a turntable, a PC, and the necessary consumables for gas metal arc welding. The setup is shown in Fig. 1.

In this setup, all safety requirements are very seriously taken into consideration. Fences are used to avoid physical contact between the robot and the operators, there are ultraviolet filters in the glasses screens around the welding area to protect the operator's eyes, and many other safety devices are incorporated, such as automatic shutoff of the robot and welding system should the fence door be opened. The PC is not highly powered as most of the tasks are considered not very 'heavy'. The two most demanding programs are the CAD and the robot simulator programs and these run perfectly on the present machine (Intel based microprocessor 80486 with $66 \mathrm{MHz}$ clock speed and 16 Mbytes of memory).

The PC does not need to be physically part of the setup. It is used to draw the component with the CAD 
program, to input some part features, to generate the welding parameters, to generate the robot program, to simulate the robot program, and to compile and download the robot program to the robot itself. Only this final task requires the $\mathrm{PC}$ to be near the robot although, even in this case, a long RS-232C serial cable can be used to link the computer to the robot.

Once the robot program is downloaded to the robot and the welding system is ready to start, the operator needs simply to press the start button and the robot begins to build up the component. An example of a component being made can be seen in Fig. Error! Reference source not found.a. A red hot track follows the welding process and cools down after a few seconds. Also note that the welding arc is bell shaped.

The resulting rectangular component can be seen in Fig. 2b. It is important to point out that this photograph was taken immediately after stopping welding. No machining or treatment of any kind had been carried out on the component.

Figure 3 shows another specimen component, in this case a manifold, and the photograph was again taken also straight immediately after welding stopped. Although the welding layers in this component were visible, the surface finish was perfectly acceptable for the purpose of this component, which was to be used as a manifold in a car exhaust.

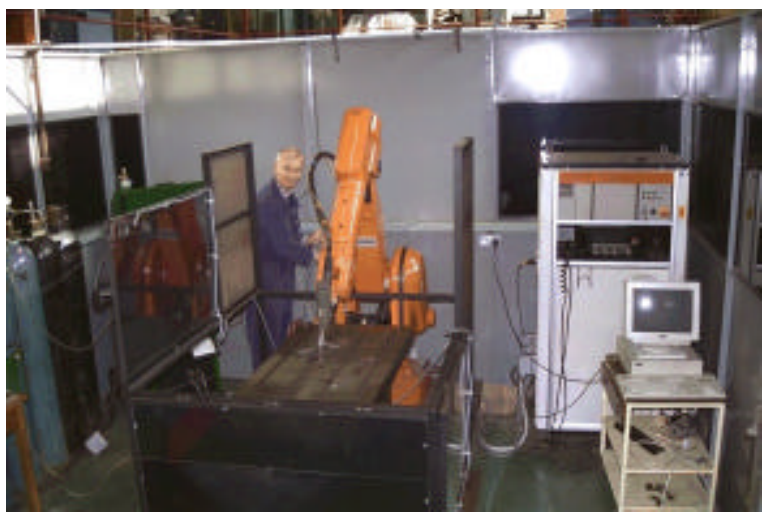

\section{Setup for Rapid Prototyping using Robot Welding}

Many other specimens have been made and some of them have been described by Ribeiro and Norrish ${ }^{6,7,8}$.

\section{WELDING PARAMETERS}

The welding parameters for the initial specimens, were calculated using a trial and error approach. First, an experienced welding technician carried out some trials to find the best welding parameters for the material, thickness, and speed desired. For each specimen, several tests needed to be undertaken, material was wasted, and the approach was time consuming.
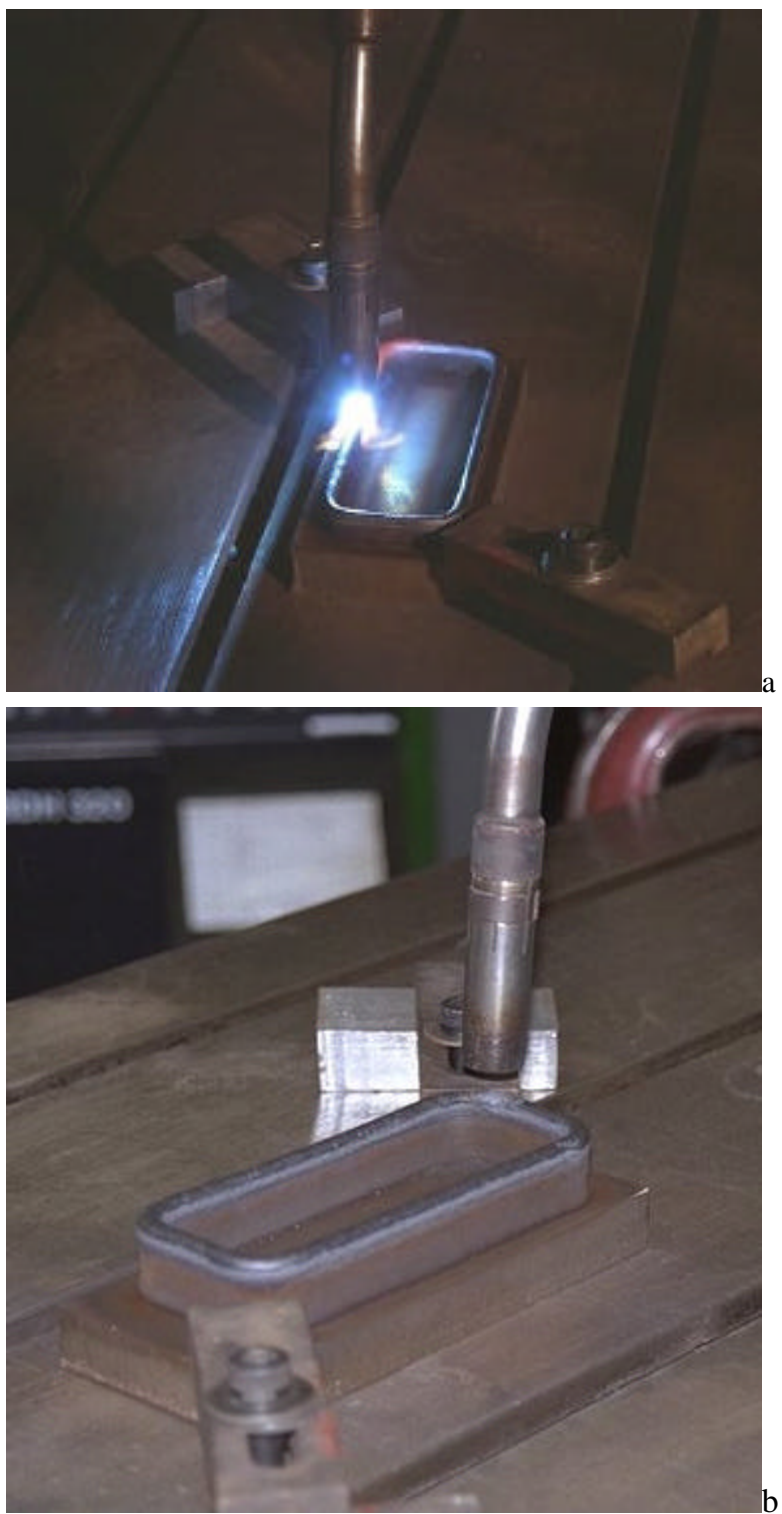

2 Rectangular component

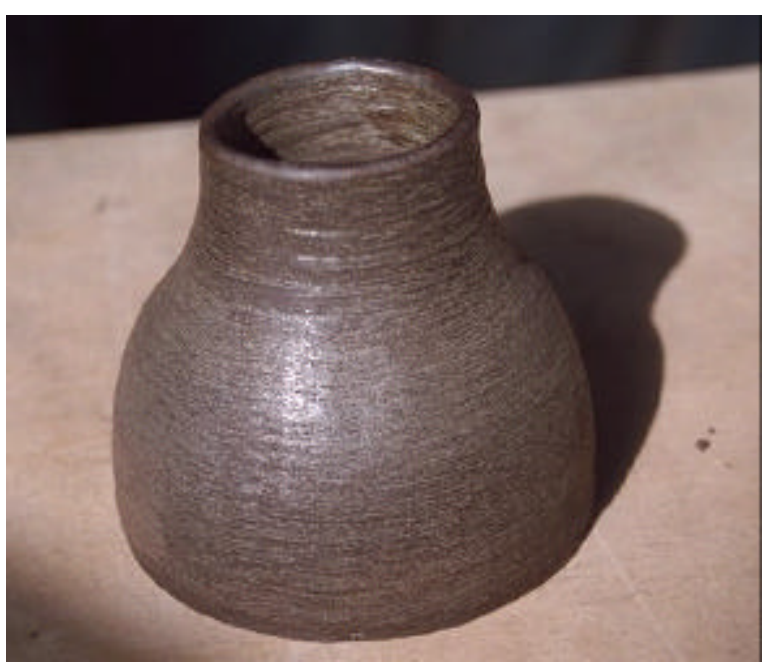


3 Manifold, photographed immediately upon completion

There was also a need to standardise the welding parameters to achieve consistent quality in the welded components and to further automate the process, as well as to facilitate the parameter selection. This could be achieved in two different ways: either by using a database containing information about different materials, different thicknesses, different gases, etc., and their respective associated welding parameters; or by using a mathematical modelling approach. The first option would lead to generation of a huge amount of information with several possible solutions and, even so, some cases could still be missing. In addition, it will take a long time to gather all the information by making specimens and analysing them, to be able to instruct the database for every case. This data gathering could also prove extremely expensive.

Using a modelling approach, the mathematical variables for every material and thickness could be kept for further use. The resulting welding parameters may be a group of possible solutions that lead to similar results, or only one solution which gives the best result. The first approach allows the user to choose between different solutions according to preference ${ }^{9}$ while the second approach selects the best possible solution making it more automated (unmanned). In the present work, the second approach (one solution only) was chosen.

The mathematical approach does not work for all possible cases unless there is a different formula for every possible material and desired wire thickness, which also complicates the process. A single formula can only be expected to work for a limited range of requirements, although it is simpler to use.

\section{WELDING DATA COLLECTION}

As the purpose of the present work was not to generate welding parameters but only to demonstrate the feasibility of rapid prototyping, it was decided to use the mathematical approach just to test the system. For this reason, only one material and one thickness were used. The material chosen was Inconel718, as most of the tests were already being carried out with this material. The wire chosen was $1.0 \mathrm{~mm}$ in diameter, as robotic welding wires are commonly between $0.8 \mathrm{~mm}$ and $1.2 \mathrm{~mm}$ in diameter.

To gather the data, it was necessary to deposit beads with controlled welding parameters. It was thus decided that, to concentrate on the parameters rather than on the shape, a cylinder would be built up with the use of a turntable. The turn table speed was controlled digitally and it had a resolution of $0.01 \mathrm{rev}$ $\min ^{-1}$. As the diameter of the cylinder was known, the speed and frequency with which the table would have to turn for each specimen was calculated according to the desired welding speed.

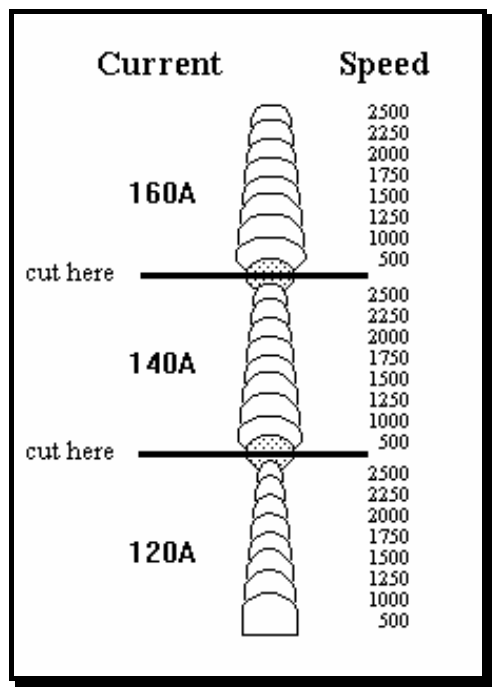

4 Cross-section of cylinder with respective welding conditions: units of speed are $\mathrm{mm} \mathrm{min}^{-1}$

This cylinder test piece was made up of groups of 10 layers with different currents and welding speeds. The current was varied between 120 and $160 \mathrm{~A}$ and the welding speed between 500 and $2500 \mathrm{~mm} \mathrm{~min}^{-1}$. The fixed characteristics of the experiment are described in Table 1.

The test was carried out using the synergic algorithm on the power source. This simplifies parameter selection and ensures stability. The synergic algorithm has a trim parameter which is used to fine tune the current-wire feed speed relationship.

The test started with the lowest current $(120 \mathrm{~A})$ and with the lowest welding speed $\left(500 \mathrm{~mm} \mathrm{~min}^{-1}\right)$. After the 10 layers were deposited, the process was stopped and the height and width were measured as well as the average welding parameters, voltage and current (from the power source). The process was stopped for 1 or 2 min only to avoid the component cooling down. The turn table speed was set to its new (faster) value and the process was repeated for the speeds of 1000, 1250, 1500, 1750, 200, 2250 and 2500 $\mathrm{mm} \min ^{-1}$.

Once all the welding speeds had been tested for the same current, it was necessary to deposit a protective layer, to be able to cut the component in that location and not destroy the specimen (which was very thin), as the first set of 10 layers of the next specimen would be much thicker than the last set of the previous specimen. The protective layer was deposited at a speed of $1750 \mathrm{~mm} \mathrm{~min}^{-1}$ as, at this speed, the deposition seemed to be more stable, but this did not influence in any way the final results of the test. 
The test was then repeated for 140 and $160 \mathrm{~A}$ following the same rules as described above for the 120 A test.

Table 1 Fixed characteristics of experiment

\begin{tabular}{ll}
\hline Material & Inconel 718 \\
Wire diameter & $1.0 \mathrm{~mm}$ \\
Gas type & Commercial Argon \\
Gas flowrate & $20 \mathrm{~L} \mathrm{~min}^{-1}$ \\
Standoff & $12-14 \mathrm{~mm}$ \\
Transfer type & Dip \\
Power Source & Migatronic BDH 550 \\
Robot & ASEA IRb 2000 \\
Cylinder Radius & $65 \mathrm{~mm}$ \\
Circle & $408.4 \mathrm{~mm}$ \\
No. Layers / specimen & 10 \\
\hline
\end{tabular}
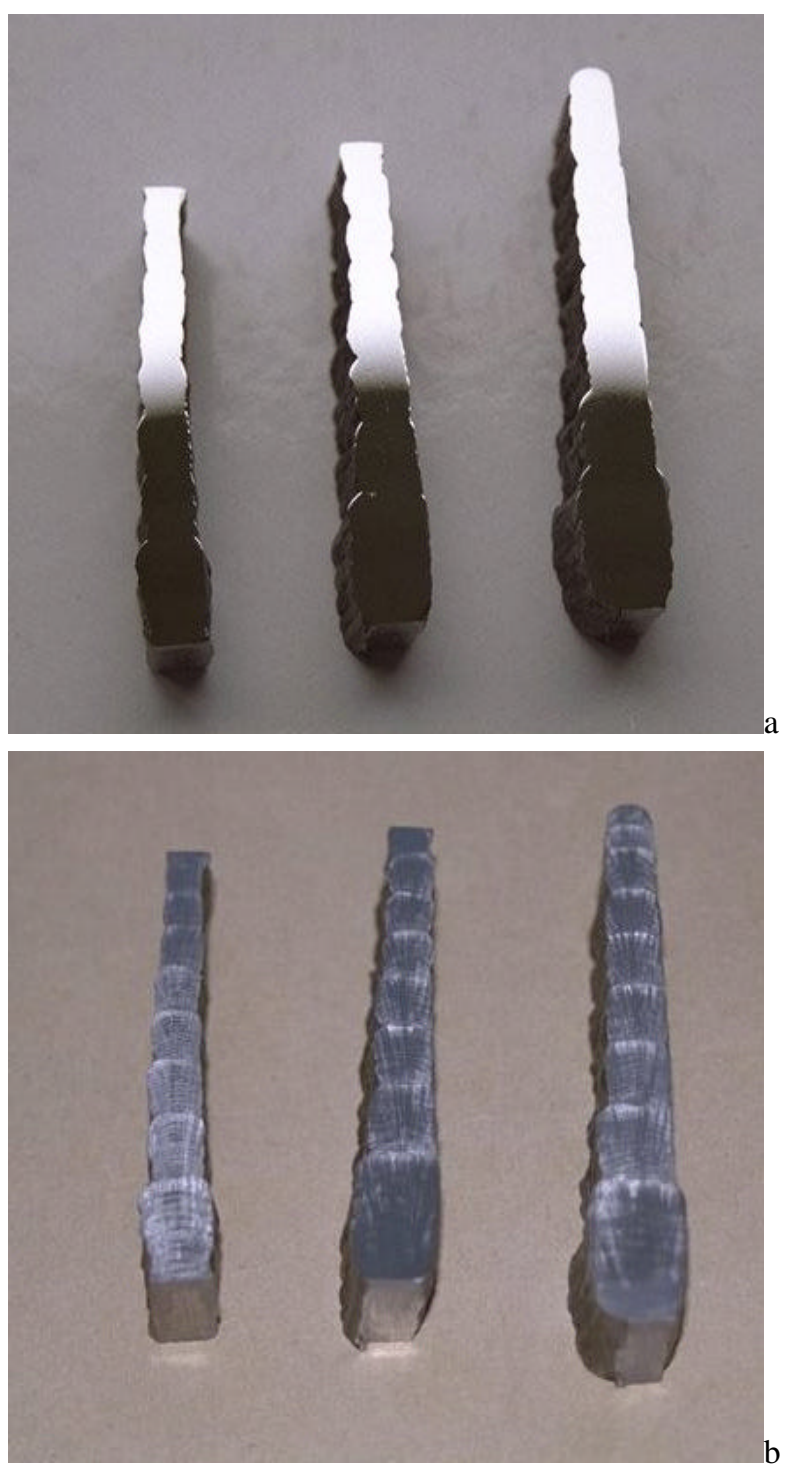

$a$ polished; $b$ etched

5 Cilindrical specimens for macro and microanalisys
Another protective layer was deposited between the 140 and the $160 \mathrm{~A}$ specimens at a speed of $1750 \mathrm{~mm}$ $\min ^{-1}$.

Figure 4 shows schematically the specimens forming the cylinder with respective welding conditions at each position. This cylinder was later cut in three as shown in fig. 4.

The three specimens were then subjected to macroand microanalysis. Before examination, they were polished (Fig. 5a) and etched (Fig. 5b). It is important to note that the welding layers were perfectly visible in the etched specimens (Fig. 5b).

A spreadsheet was created with all the measured results including bead width and height, welding voltage and current, and turntable speed and rate of rotation; charts comparing the results were created to facilitate the study.

In summary, it was found that the bead width varied between 3.8 and $10 \mathrm{~mm}$ and the height between 1.24 and $0.44 \mathrm{~mm}$ per layer. As can be seen in Figure 6, the bead width was dependent on both the welding speed and welding current, which meant that the bead geometry could be calculated. The next step was to formulate the model by converting these results to a mathematical function.

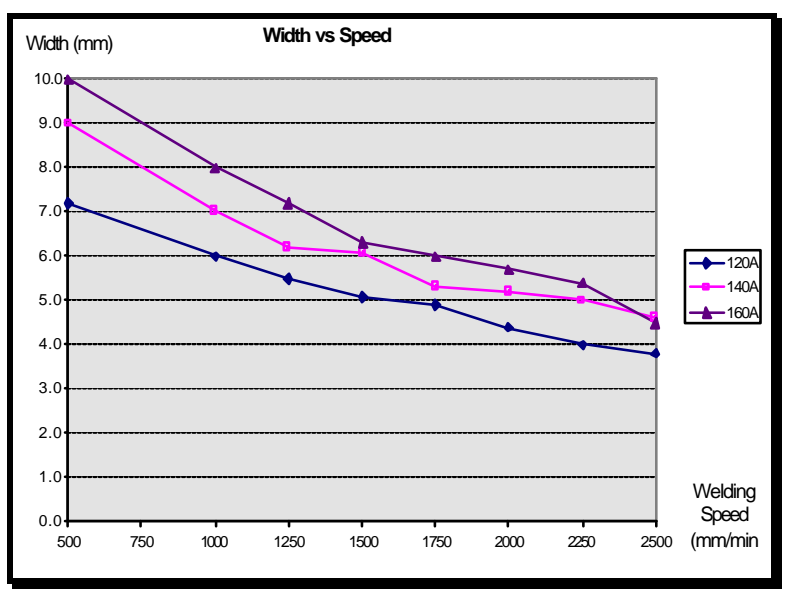

6 Effect of weldingspeed on bead width for given welding currents

\section{MATHEMATICAL MODEL DERIVATION}

All the values retrieved from the present experiment were analysed using Statgraphics and Excel software; the results were the same and, therefore, only the Excel attempt is described here.

In an Excel spreadsheet, four columns were created: Current, Welding Speed, Height and Width. The 24 respective data items gathered in the present tests were then entered in each column. A correlation of the 
values was performed. Table 2 shows the coefficients of correlation between all the variables.

Table 2 Coefficients of Correlation

\begin{tabular}{|c|c|c|c|c|}
\hline & $\begin{array}{l}\text { Welding } \\
\text { Current }\end{array}$ & $\begin{array}{c}\text { Welding } \\
\text { Speed }\end{array}$ & Bead Widtl & $\begin{array}{l}\text { h Bead } \\
\text { Height }\end{array}$ \\
\hline Weld. Current & 1 & .. & $\ldots$ & $\cdots$ \\
\hline Weld. Speed & 0 & 1 & $\ldots$ & $\ldots$ \\
\hline Bead Width & 0.417482 & -0.86724 & 1 & $\ldots$ \\
\hline Bead Height & 0.101442 & -0.89203 & 0.888184 & 1 \\
\hline
\end{tabular}

As expected, it was found that there was some correlation between the variables, especially between the welding speed and the bead geometry (width and height) with correlation values varying between 86 and $89 \%$. This was followed by a regression analysis.

As the variables involved have substantially different levels of variation (current varied between 120 and $160 \mathrm{~A}$ and welding speed varied between 500 and $2500 \mathrm{~mm} \mathrm{~min}^{-1}$ ), it was decided to use the natural logarithmic approach to reduce this discrepancy, otherwise variables with higher values could have a heavier influence in the regression analysis. Therefore, the entire data set was transformed into natural logarithmic form. A new correlation analysis was performed using the natural logarithmic values and the results from this trial gave even higher correlation, with values varying between 87 and $96 \%$.

The regression analysis was performed for the width and for the height. If a logarithmic approach is to be used, the final formula for regression analysis needs some modifications as explained below. The equations used were

$$
\begin{aligned}
& Y=\beta_{0}+\beta_{1} \cdot I+\beta_{2} \cdot S \\
& \ln Y=\ln \left(\alpha_{0}\right)+\alpha_{1} \cdot \ln (I)+\alpha_{2} \cdot \ln (S) \\
& \ln Y=\ln \left(\alpha_{0}\right)+\ln \left(I^{\alpha_{1}}\right)+\ln \left(S^{\alpha_{2}}\right) \\
& \ln Y=\ln \left(\alpha_{0} \cdot I^{\alpha_{1}} \cdot S^{\alpha_{2}}\right) \\
& Y=\alpha_{0} \cdot I^{\alpha_{1}} \cdot S^{\alpha_{2}}
\end{aligned}
$$

where $\mathrm{Y}$ is the width or the height, $\mathrm{I}$ is the Welding Current, $\mathrm{S}$ is the Welding Speed, and $\alpha 0, \alpha 1$ and $\alpha 2$ are the coefficients to be calculated from the regression analysis; $\alpha 0$ is the intersection coefficient, $\alpha 1$ is the Welding Current coefficient and $\alpha 2$ is the Welding Speed coefficient.

The final values for the coefficients were thus obtained and the results for width and height are given in Table 3. If these coefficients are substituted into equation (5), the resulting formulae are for width and height respectively

Table 3 Resulting coefficients for Width and Height

\begin{tabular}{lll}
\hline & \multicolumn{2}{c}{ Coefficients } \\
\cline { 2 - 3 } & \multicolumn{1}{c}{ Width } & \multicolumn{1}{c}{ Height } \\
\hline Intercept & 0 & 2.274873929 \\
Current & 0.968322179 & 0.335683253 \\
Weld Speed & -0.416249715 & -0.602960284 \\
\hline
\end{tabular}

If these coefficients are substituted into equation (5), the resulting formulae are for width and height respectively

$Y=e^{0} \cdot I^{0.968322179} \cdot S^{-0.416249715}$
$Y=e^{2.274873929} \cdot I^{0.335683253} \cdot S^{-0.602960284}$

Simplifying gives for width and height respectively

$$
\begin{aligned}
& Y=I^{0.968322179} \cdot S^{-0.416249715} \\
& Y=9.726692681 \cdot I^{0.335683253} \cdot S^{-0.602960284}
\end{aligned}
$$

The main objective of this mathematical approach it to obtain the welding parameters as functions of the bead geometry, but the above formulae are in the opposite form

$$
\begin{aligned}
& \text { Width }=f(\text { Current }, \text { Speed }) \\
& \text { Height }=f(\text { Current }, \text { Speed })
\end{aligned}
$$

Therefore, these formulae have to be solved to give the welding parameters as functions of the bead geometry, or

$$
\begin{aligned}
& \text { Current }=f(\text { Width }, \text { Height }) \\
& \text { Speed }=f(\text { Width, Height })
\end{aligned}
$$

Considering the general formulae for width $\mathrm{w}$ and height $\mathrm{h}$ to be

$$
w=k 1 \cdot c^{k 2} \cdot s^{k 3}
$$


$h=k 4 \cdot c^{k 5} \cdot s^{k 6}$

where $\mathrm{c}$ is current, $\mathrm{s}$ speed, and $\mathrm{k}_{1}, \mathrm{k}_{2}, \mathrm{k}_{3}, \mathrm{k}_{4}, \mathrm{k}_{5}$, and $\mathrm{k}_{6}$ are constants. First, taking equation (14) and solving it for current $\mathrm{c}$ gives

$c=\left(\frac{w}{k 1 \cdot s^{k 3}}\right)^{\left(\frac{1}{k 2}\right)}$

Then, substituting for $\mathrm{c}$ in equation (15) gives

$$
h=k 4 \cdot\left[\left(\frac{w}{k 1 \cdot s^{k 3}}\right)^{\left(\frac{1}{k 2}\right)}\right]^{k 5} \cdot s^{k 6}
$$

Simplify gives

$h=k 4 \cdot w^{\left(\frac{k 5}{k 2}\right)} \cdot k 1^{\left(-\frac{k 5}{k 2}\right)} \cdot s^{\left(\frac{(k 2 \cdot k 6-k 3 \cdot k 5)}{k 2}\right)}$

Now, solving to obtain speed $\mathrm{s}$ gives

$$
s=\left(\frac{h}{k 4 \cdot w^{\left(\frac{k 5}{k 2}\right)} \cdot k 1^{\left(-\frac{k 5}{k 2}\right)}}\right)^{\left(\frac{k 2}{(k 2 \cdot k 6-k 3 \cdot k 5)}\right)}
$$

and, finally, simplifying gives

$$
s=h^{\left(\frac{k 2}{(k 2 k 6-k 3 k 5)}\right)} \cdot k 4^{\left(\frac{-k 2}{(k 2 k 6-k 3 k 5)}\right)} \cdot w^{\left(\frac{-k 5}{(k 2 k 6-k 3 k 5)}\right)} \cdot k 1^{\left(\frac{k 5}{(k 2 k 6-k 3 k 5)}\right)}
$$

The formula to calculate $\mathrm{s}$ is now obtained as a function of $w$ and $h$.

As $s$ is known, its value can be substituted in equation (14) and, therefore, $c$ can be calculated from

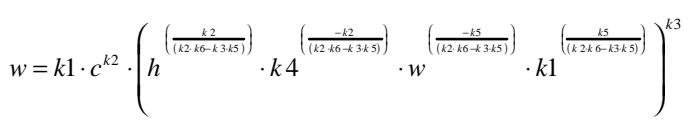

Solving for variable $c$ and simplifying, the result is very similar to equation (20)

$$
c=h^{\left(\frac{-k 3}{(1 k 2 \cdot k-k 3 \cdot k 5)}\right)} \cdot k 4^{\left(\frac{k 3}{(k 2 \cdot k 6-k 3 \cdot k 5)}\right)} \cdot w^{\left(\frac{k 6}{(k 2 \cdot k 6-k 3 k 5)}\right)} \cdot k 1^{\left(\frac{-k 6}{(k 2 \cdot k 6-k 3 k 5)}\right)}
$$

The formula to calculate the $c$ is now obtained as a function of the width and height of the welding bead.

These formulae can be even further simplified. Considering

$$
\alpha=(k 2 \cdot k 6-k 3 \cdot k 5)
$$

equations (20) and (22) can be written as

$$
\begin{aligned}
& c=h^{\left(\frac{-k 3}{\alpha}\right)} \cdot k 4^{\left(\frac{k 3}{\alpha}\right)} \cdot w^{\left(\frac{k 6}{\alpha}\right)} \cdot k 1^{\left(\frac{-k 6}{\alpha}\right)} \\
& S=h^{\left(\frac{k 2}{\alpha}\right)} \cdot k 4^{\left(\frac{-k 2}{\alpha}\right)} \cdot w^{\left(\frac{-k 5}{\alpha}\right)} \cdot k 1^{\left(\frac{k 5}{\alpha}\right)}
\end{aligned}
$$

\section{MATHEMATICAL MODEL USAGE}

To test the veracity of the above formulae, a $\mathrm{C}$ language program and a BASIC program were written and some tests were carried out to compare the formulae with the experimental results.

Should the material, wire thickness or any other of the fixed parameters be changed, the specimens and formulae would have to be re-evaluated, but to avoid reprogramming the formulae in the slicing routines, the coefficients were put into a text file which can be easily edited. This file is called CONST.INS and contains the coefficient values for the above formulae as well as other parameters. An example of this file is given in Table 4.

Table 4 Typical CONST.INS file containing welding formulae coefficients

\begin{tabular}{lll}
\hline 0.11 & ; RATIO Height \\
1.00000 & $; \mathrm{K} 1$ & width \\
0.968322 & $; \mathrm{K} 2$ & width \\
-0.41625 & $; \mathrm{K} 3$ & width \\
9.7266925 & $; \mathrm{K} 4$ & height \\
0.335683 & $; \mathrm{K} 5$ & height \\
-0.60296 & $; \mathrm{K} 6$ & height \\
95.0 & $;$ Imin & \\
160.0 & $;$ Imax & \\
4.0 & $;$ WFSmin & \\
7.4 & ; WFSmax & \\
\hline
\end{tabular}

In practice, in the slicing routines, the only parameter that the user needs to input is the width of the bead. The height is considered to be 0.11 times the width and was assumed after taking the average of all the specimens. This ratio avoids the user having to decide the height value per layer, as most of the height/width ratios were found to be between 0.09 and 0.13. However, this number can be changed if necessary. It is represented in the CONST.INS file given in Table 4 by the first line (ratio) so there is no need to reprogramme the routines if this number needs to be changed. 


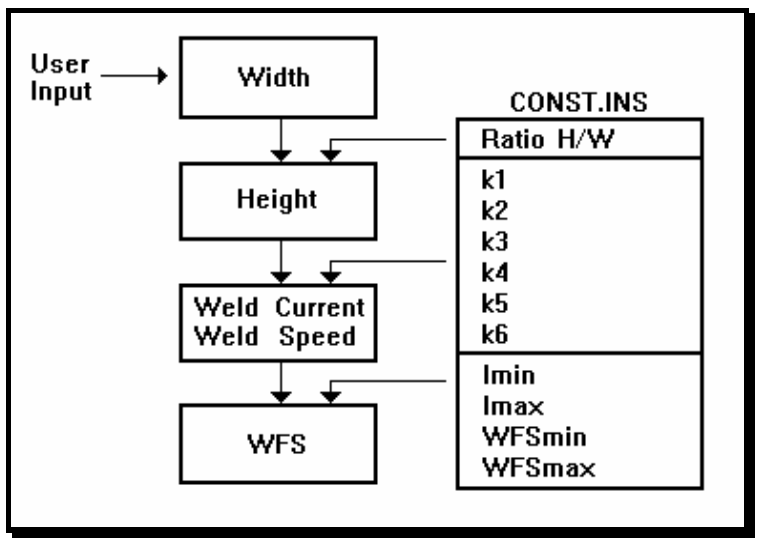

3 Automatic generation of welding parameters and CONST.INS file

As shown schematically in Fig. 3, most of the parameters are linked and dependent on others previously calculated. First, the user inputs the thickness of the bead. Automatically, the program calculates the height of the bead according to the ratio value stored in the CONST.INS file. Once the program has the width and height, it can then calculate the welding current and speed according to the coefficients $k_{1}-k_{6}$ also stored in the CONST.INS file. Once, the welding current is known, the wire feed speed can also be calculated with the help of the remaining parameters in the CONST.INS text file.

For this procedure to work, the power source must use a synergic program. The synergic program includes a pre-determined relationship between the welding variables in the case of current and wire feed speed, which is schematically shown in Fig. 4. The coefficients of the equation for the straight line may be stored in the CONST.INS file (see Table 4) for the program to be able to calculate the wire feed speed.

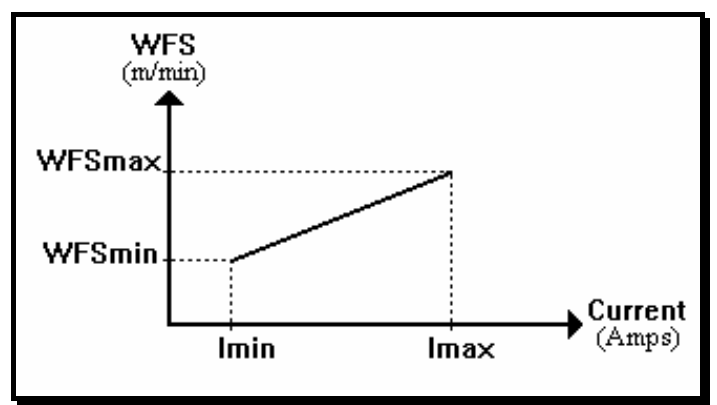

4 Synergic current-wire feed speed conversion chart

This CONST.INS file contains all the necessary information to calculate this sequence of linked parameters and all these values can be edited at any time according to the user's needs. It is also important to point out that, although the program automatically sets up all the welding parameters, if the user does not agree with them, it is possible to edit and change them in the part features menu to any other desired. The intention is only to automate the input task as much as possible.

\section{WELDING FORMULAE TEST}

To test the formulae derived above, a component was made with three parts, each part having a different width. The first part was programmed to be $6 \mathrm{~mm}$ (part A), the second $8 \mathrm{~mm}$ (part B), and the third $10 \mathrm{~mm}$ in width (part C). Table 4 gives the expected values, the achieved values, and the error.

Table 4 Width formulae test results

\begin{tabular}{lccc}
\hline & $\begin{array}{c}\text { Expected } \\
\text { width, mm }\end{array}$ & $\begin{array}{c}\text { Achieved } \\
\text { width, mm }\end{array}$ & $\begin{array}{c}\text { Absolute } \\
\text { error, mm }\end{array}$ \\
\hline Part A & 6.0 & 6.2 & 0.2 \\
Part B & 8.0 & 8.4 & 0.4 \\
Part C & 10.0 & 10.2 & 0.2 \\
\hline
\end{tabular}

The errors are relatively small considering the relatively poor surface finish of a welded component. Another important aspect is that all the errors are positive or, in other words, all the part widths were larger than expected. This can be explained as, when making the specimens to generate the formulae, the robot was stopped after every speed-current combination for measurement taking. This pause allowed the component to cool down. The specimen made to test the formulae was completed without stopping the welding, which meant that the component did not cool down between weld layer deposits. The heat buildup, therefore, was higher in this case, causing increased deposition. This could be the reason for all the errors being positive.

\section{CONCLUSIONS}

A mathematical procedure has been created to automatically calculate welding parameters for RPURW. These formulae are integrated within the slicing routines to simplify and automate the entire process as much as possible. When the user inputs the information for the part, the optimum welding parameters as given by the formulae are assumed as default values, although the operator still has the facility for selecting his or her own parameters, should this be required.

The tests were carried out with a fixed material, gas, and power source; a prediction algorithm was created using regression analysis. The limitation with this approach is that only one solution is generated, although more than one solution can exist. 
The formulae are based on coefficients which are stored in a text file. This formulae only work with the particular power source, material and gas used in the test. If any of these change, the test needs to be carried out again and new coefficients have to be calculated. These can then be input into the text file to allow the system to work for the new condition just tested. This eliminates the need to reprogram the routines if any of the coefficients change.

If the values in the CONST.INS setup file are incorrectly input, the results will be unexpected. Therefore, care must be taken in any attempt to edit and change this very important file.

If, for some reason, the user does not want to use the welding parameters generated by the routines, it is possible to override these and use his or her own parameters. The function of the preset parameters is only to help the inexperienced user. Many welders have experience of fine tuning welding parameters and, sometimes, this works better than a straightforward result from a formula.

It can be seen that the variables are linked in a certain order, which means that if one variable is incorrectly input all its dependent variables will also be incorrect.

\section{ACKNOWLEDGEMENTS}

One of the authors (FR) would like to thank Professor J. Norrish for his support of this project and his expertise in the welding field. Dr. Babatunde Ogunbiyi is especially thanked for his assistance with the welding parameters. J. Savill is also thanked for his strong support in welding all of the components and for solving in an efficient way the practical problems that arose, as well as encouraging new ideas. The author would also like to thank his wife for her understanding during the difficult periods of this project.

\section{REFERENCES}

1 P. M. Dickens, R. C. Cobb, I. Gibson and M. S. Pridham: J. Des. Manuf., 1993, 3, (1), 39-44.

2 P. M. Dickens, M. S. Pridham, R. C. Cobb and I. Gibson: '3-D Welding', Internet, www.cranfield.ac.uk/ aero/rapid/PROCEEDING/dickens1.html, Cranfield University, Cranfield, UK.

3 A. F. Ribeiro and J. Norrish: in 'Solid Freeform Fabrication 1996 Symposium', Austin, TX, USA, August 1996, 249; 1996, Austin, TX, University of Texas at Austin.

4 A. F. Ribeiro and J. Norrish: Proc. conf. ICMA'97, Hong Kong, April 1997, Vol. 1, 443.

5 A. F. Ribeiro and J. Norrish: Proc. conf. 3rd France-Japan Cong. and 1st Europe-Asia Cong., Besançon, France, October 1996, 76

6 A. F. Ribeiro and J. Norrish: Proc. 5th Bienn. Int. Conf. on Computer Technology in Welding, Paris, France, June 1994, TWI, paper 55.

7 A. F. Ribeiro and J. Norrish: Proc. 6th Bienn. Int. Conf. on Computer Technology in Welding, Lanaken, Belgium, June 1996, TWI, paper 60.

8 A. F. Ribeiro and J. Norrish: Proc. 27th Int. Symp. on Industrial Robotics, Milan, Italy, October 1996, 275.

9 B. Ogunbiyi, J. Norrish: Proc. 6th Int. Conf. on Joining of Materials, Helsingnor, Denmark, April 1993. 